\title{
TSC2 Monoallelic Inactivation
}

National Cancer Institute

\section{Source}

National Cancer Institute. TSC2 Monoallelic Inactivation. NCI Thesaurus. Code C157747.

Any gain, loss, or exchange of DNA that results in monoallelic loss of function mutations

in the TSC2 gene. 